\title{
Effect of Heat Treatment on Hardness of Aluminium Alloy Reinforced with Rice Husk Ash
}

\author{
Archana Somnath Sangale \\ M.E. Student Department of Mechanical Engineering \\ Vignharta Trusts Shivajirao \\ S. Jondhale College of Engineering \& Technology, \\ Shahapur, Asangaon.
}

\author{
Arun M. Kulkarni \\ Assistant Professor of Mechanical Engineering \\ Vignharta Trusts Shivajirao \\ S. Jondhale College of Engineering, Dombivli.
}

\begin{abstract}
Metal matrix composites are the materials in which reinforcement materials are added to improve their properties. The main problem associated with the Metal Matrix Composites is the high cost of reinforcement material. To overcome this obstacle, a need arises to look for low cost reinforcements like Rice Husk Ash (RHA), Fly Ash, etc. In the present paper, the Mechanical Properties of aluminum Al6061 reinforced with RHA and fabricated by stir casting technique are studied. The volume fraction of RHA reinforcement is varied in the range of $4-12 \%$ by volume. The hardness test was conducted on Rockwell hardness testing machine. For As cast samples it is observed that hardness of the alloy increases with increase in volume fraction of the reinforcement. Further Studied the effect of heat treatment on Al-RHA Composites. Normalizing and Quenching Heat treatment process was carried on the samples. Due to Heat treatment it is observed that the hardness values are further more increased. From the studies, it can be concluded that addition of RHA reinforcement improved the hardness values of aluminum Al6061 alloy and due to heat treatment the more improved hardness values are observed.
\end{abstract}

Keywords-Rice Husk Ash, Hardness, Heat Treatment

\section{INTRODUCTION}

From last few years there has been a rapid increase in utilization of aluminum alloy in Industries due to its unique property of light weight and low cost. Different types of reinforcing materials are added to aluminum alloys to improve the properties. The reinforcing materials are broadly classified as Ceramic Synthetic particulates, Industrial wastes and Agro wastes derivatives. Most of the engineering applications require materials that are stronger, lighter and less expensive. A good example, is the current research in the development of materials, that have good strength to weight ratio, suitable for automobile applications where fuel economy with improved engine performance are becoming more critical [1]. The aluminum matrix composites (AMCs) represent a class of MMCs possessing properties like low density, high stiffness and strength, superior wear resistance, controlled co-efficient of thermal expansion, higher fatigue resistance and better stability at elevated temperature. Due to this, these composites are used for the design of a wide range of components for advanced applications [2]. It has been found that the use of AMCs in engine applications can reduce the overall weight, fuel consumption and pollution in the automobiles and aircrafts $[3,4]$. AMCs reinforced with either silicon carbide or alumina particles are attractive materials for such applications [3-5]. The use of inexpensive reinforcements and natural materials will reduce the cost of AMCs and increases its application [4]. Therefore now-a-days most of the research going on Agro-Waste, as they are easily available, low cost, low density, reduced environmental pollution. These agrowaste ashes often contain a high percentage of silica $\left(\mathrm{SiO}_{2}\right)$ with a distribution of other refractory oxides such as $\mathrm{Al}_{2} \mathrm{O}_{3}$ and hematite $\left(\mathrm{Fe}_{2} \mathrm{O}_{3}\right)$ [6,7]. For Development of AMCs Stir casting is one of the liquid methods which is being extensively used. [8]. In the present work, an attempt is made to produce aluminum alloy AA6061 reinforced with RHA particles by Stir Casting method and study the mechanical and Tribological properties of AA6061-RHA AMCs.

\section{LITERATURE SURVEY}

Gladston et. al. [1] developed composite using aluminum alloy AA6061 reinforced with various amounts $(0,2 \%, 4 \%, 6 \%$ and $8 \%)$ mass fraction of RHA particles using Compo-casting method. It was observed that reinforcement of RHA particles enhanced the microhardness and ultimate tensile strength (UTS) of the AMCs. Alaneme et. al. [2] carried out two steps stir casting method for development of AMCs with reinforcing material as RHA \& $\mathrm{Al}_{2} \mathrm{O}_{3}$. it is observed that the hardness of the hybrid composites decreases slightly with increase in RHA content.

Mittal et al. [3] studied Mechanical Properties of AlRHA-Cu conclude that the specimens containing copper shows improved values for hardness than specimens containing only rice husk ash.

Prasad et al. [4] fabricated AMCs used reinforce material as rice husk and fly ash particles of 5\%,10\% and $15 \%$ each by weight using stir casting technique. It is observed that the tensile strength and hardness increases up to a certain value.

\section{METHODOLOGY}

\section{1. fabrication process:}

Stir casting method is a liquid state method of fabricating composite materials. For the present study the composite Al6061-RHA metal matrix composites with three different volume fractions were fabricated using stir casting process. Aluminium alloy (Al6061), is used as base metal 
that has been reinforced with 4, 8, 12 wt. \% of RHA particles. Initially small chunks of A16061 was inserted in graphite crucible and melted at $800^{\circ} \mathrm{C}$ in a furnace. Simultaneously, RHA particles are also preheated in another furnace up to $600^{\circ} \mathrm{C}$ to remove the moisture and organic constituents. Then measured quantities of preheated RHA particles were add into the molten aluminium alloy. Then with the help of a mechanical stirrer which is driven by electric motor, stirring was carried out with speed of 700-800 rpm. Stirring was continued for 5-8 min so that all the RHA particles mix uniformly into the molten aluminium alloy. The mixture was then poured into a permanent die at room temperature. The pouring temperature was kept slightly above the casting temperature to enhance fluidity. The casting composition done for different samples are shown in table 1 and a pictorial representation of the samples prepared for tensile testing is also shown in fig. 1.

Fig. 1 - Samples

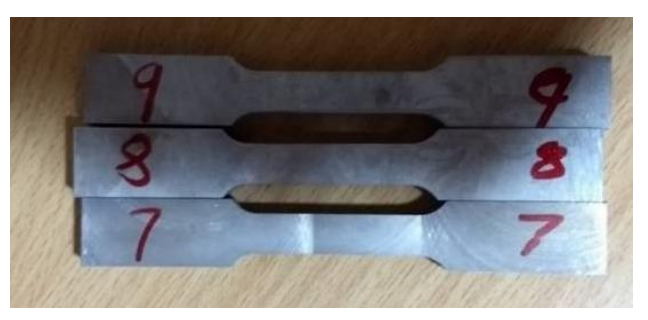

Table 1- Composition of samples prepared.

\begin{tabular}{cc}
\hline Sample No. & Composition \\
\hline 1 & $\mathrm{Al}+4 \%$ RHA \\
2 & $\mathrm{Al}+8 \%$ RHA \\
3 & $\mathrm{Al}+12 \%$ RHA \\
\hline
\end{tabular}

III. RESULT ANALYSIS

\section{Hardness: -}

The hardness tests of the composites are carried out using Rockwell hardness testing machine. Before the test, the samples were cleaned to remove dirt, scratches etc. A Steel ball of 1/16" diameter used as indenter, two levels of force are applied to indenter i.e. minor load of $10 \mathrm{kgf}$ and major load of $100 \mathrm{kgf}$ for a duration of 20 seconds. The study suggests that the hardness increases with increase in volume fraction of RHA reinforcement. The reinforcing particles are harder and stiffer than the matrix, the composites resistance to plastic deformation caused by the indenter increases. The results of hardness testing for as cast samples are shown graphically in fig. 2 .

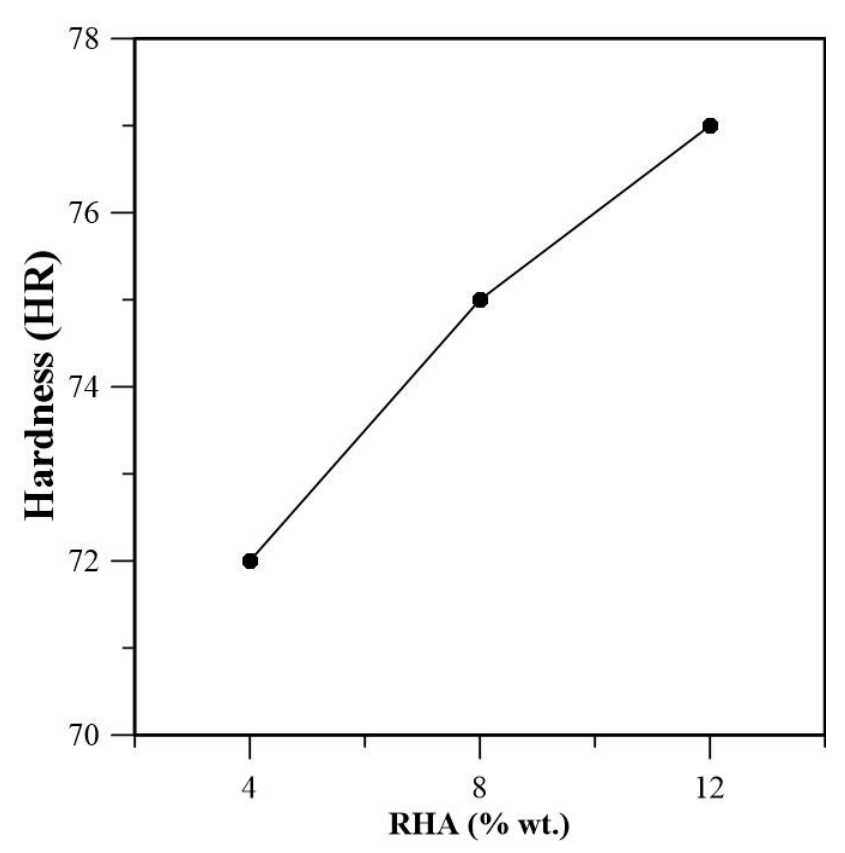

figure 2 :hardness value for as cast

Therefore, Heat treatment on samples was conducted. It is a thermal process through which hardening or softening of the material can be achieved. Firstly, for normalizing process, Al-RHA samples were heated in furnace at temperature $150^{\circ} \mathrm{C}$ for 2 hours then the samples were allowed to cool back to room temperature by exposing it to room temperature air. Holding time long enough for transformation occur. Due to normalizing, it is observed that the hardness of material increased, this is due thermal effect which changed the microstructure of samples. Quenching process was carried out on Al-RHA samples. For that samples were heated in furnace at temperature $150^{\circ} \mathrm{C}$ for 2 hours then the samples quenched in water. Due to rapid cooling, it is observed that the hardness of material increased further more as compared to as cast samples and normalizing heat-treated samples. This is due to rapid cooling of the samples. the microstructure changes in the materials.

Table. 2: - Rockwell hardness value for as cast, Normalizing and Quenching Heat Treatment samples

\begin{tabular}{|l|l|c|c|c|}
\hline \multirow{2}{*}{$\begin{array}{c}\text { Sample } \\
\text { No. }\end{array}$} & Compositions & \multicolumn{3}{|c|}{ Rockwell Hardness Values (HR) } \\
\cline { 3 - 5 } & & $\begin{array}{c}\text { As } \\
\text { Cast }\end{array}$ & $\begin{array}{c}\text { Normalizing } \\
\text { Heat } \\
\text { Treatment }\end{array}$ & $\begin{array}{c}\text { Quenching } \\
\text { Heat } \\
\text { Treatment }\end{array}$ \\
\hline 1 & $\mathrm{Al}+4 \%$ RHA & 72 & 90.66 & 105.66 \\
\hline 2 & $\mathrm{Al}+8 \%$ RHA & 75 & 102 & 103 \\
\hline 3 & $\begin{array}{l}\mathrm{Al}+12 \% \\
\text { RHA }\end{array}$ & 77 & 89.66 & 94 \\
\hline
\end{tabular}




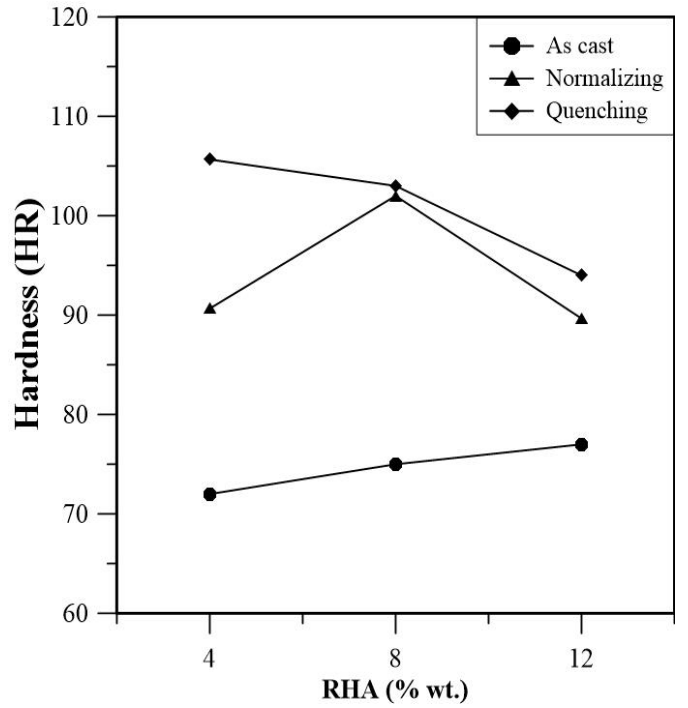

Fig. 3 - Hardness Values of Al6061/RHA AMCs (For as Cast, Normalizing, Quenching samples)

From the experimental results, it can observe that due to heat treatment of Al-RHA samples, Hardness values increases for all the composite samples. Percentage increase in hardness value for AL-4\% RHA sample is more compared to other composite samples (Fig.3.)whereas the Percentage increase in hardness value is less for $\mathrm{AL}-12 \%$ RHA composite sample. Quenched samples show the maximum hardness values compared to Normalized heat-treated samples.

\section{CONCLUSION}

From the present study the following conclusions can be made

- Hardness increases with increase in volume fraction of RHA reinforcement.

- Due to Heat treatment, Hardness of AL-RHA composites samples increases.

- Effect quenching heat treatment is more effect on composite samples compared to normalizing process

- Thus, RHA particles can be used as reinforcement material to improve the Mechanical properties of the aluminum alloy.

\section{REFERENCES:}

[1] Tjong, S. C. (2014). Processing and deformation characteristics of metals reinforced with ceramic nanoparticles. In Nanocrystalline Materials (Second Edition)(pp. 269-304).

[2] Surappa, M. K. (2003). Aluminium matrix composites: Challenges and opportunities. Sadhana, 28 (1-2), 319-334.

[3] Macke, A., Schultz, B. F., \& Rohatgi, P. (2012). Metal matrix composites. Adv. Mater. Processes, 170(3), 19-23.

[4] Christy, T. V., Murugan, N., \& Kumar, S. (2010). A comparative study on the microstructures and mechanical properties of Al 6061 alloy and the MMC Al 6061/TiB2/12p. Journal of Minerals and Materials Characterization and Engineering, 9(01), 57.

[5] Miracle, D. B. (2005). Metal matrix composites-from science to technological significance Composites science and technology, 65(15-16), 2526-2540.

[6] Madakson, P. B., Yawas, D. S., \& Apasi, A. (2012) Characterization of coconut shell ash for potential utilization in metal matrix composites for automotive applications. International journal of engineering science and technology, 4(3), 1190-1198. 